\title{
Intelligent Communication Management Terminal in the Construction of Human Resource Management Mode
}

\author{
Shumei Wu \\ College of Management, Wanjiang University of Technology, Ma'anshan, 243000 Anhui, China \\ Correspondence should be addressed to Shumei Wu; wt12039@wjut.edu.cn
}

Received 6 August 2021; Revised 20 October 2021; Accepted 1 November 2021; Published 23 November 2021

Academic Editor: Zhihan Lv

Copyright ( 2021 Shumei Wu. This is an open access article distributed under the Creative Commons Attribution License, which permits unrestricted use, distribution, and reproduction in any medium, provided the original work is properly cited.

\begin{abstract}
With the rapid development of the economy, the integration of corporate strategic management and human resource management has become an issue of concern. This research mainly discusses the role of intelligent communication management terminal in the construction of human resource management mode. In this research, the system development process of this research mainly uses the class library in the software architecture layer to support the software development process. The main development language of Android, JAVA, is to install the Android Develop Tools plug-in on eclipse and install the Android SDK in the computer operating system to build the Android development environment. The development and application of the system not only make the enterprise managers more convenient and efficient in the process of managing the enterprise but also smooth the operation of the enterprise while reducing the human resource investment and also gives the employees more right to know and the right to participate in the enterprise construction. By creating more value while reducing human resource input, enterprises will enable it to obtain more benefits, and thus enter a cycle of good development and contribute to society. The system has the functions of personnel management, recruitment management, attendance management, training management, work management, and salary management. The recruitment management function of the system is mainly composed of recruitment plan management, recruitment information management, and talent pool. In the system's recruitment plan management function, important information such as the recruitment part, the number of recruits, personnel requirements, and the specific arrival time of the personnel must be clarified. The personnel in charge of the enterprise personnel department shall conduct corresponding regulations according to the specific needs of the enterprise and shall be experienced by the personnel department. The review is carried out, and all parts of the enterprise are coordinated and completed at the same time. In the platform performance test, when the number of concurrent users reaches 50000, the request time is about 6 seconds, which meets the requirement that the response time of 10000 people per second is less than 10 seconds. This research puts forward suggestions and countermeasures for the optimization of human resource management, which can not only improve the efficiency of Y company's human resource management but also provide useful reference and reference for other enterprises facing the same problem.
\end{abstract}

\section{Introduction}

Scientific human resource management concept originated in western countries, human resource management information system is evolved from the western "electronic archives," and foreign human resource management information system from the 1960s, after decades of development, has been more comprehensive integrated into the advanced thought of human resource management and scientific theory. At present, there are not many studies that focus on corporate social responsibility or corporate social responsibility practices from the perspective of human resource management in the Chinese context, especially at the organizational level, which discusses corporate social responsibility practices from the perspective of employees. In addition, it is very necessary to discuss the impact of corporate social responsibility on human resource management and organizational performance in the context of China. System with the continuous development of computer science and technology, computer software, and hardware level 
is constantly updated and perfect, computer application popularity is also improving, the human resource management information system has gradually solved the main problems in the first stage, while some simple financial functions, compensation, and report functions are reflected, but due to the human resource management field involved unfamiliar and lack of professional knowledge restrictions $[1,2]$.

Due to the fierce competition in the talent market, human resource management has been increasingly paid attention to and has become one of the internal core management affairs of each enterprise. The demand for human resources management information system in all walks of life has become more urgent and has higher target requirements. In this period, the development of human resources management information system can be considered from the professional perspective of human resources management, unified management of information input and data storage for unified management, and some financial functions and other data calculation, and the use interface of the system is more friendly. The main problem to be solved in this article is how to solve the "information island" of the human resources market, realize the interaction between the human resources market online and offline, and realize the interconnection and intercommunication of the human resources market public services and labor management systems; how to use self-service terminals and mobile terminals and other equipment realize the expansion of public employment service channels; how to realize the Internet, informatization, and integration of the human resources market according to user needs. At this time has entered the era of information development, with the continuous improvement of computer science and technology, especially the renewal of information technology and the wide application of Internet technology, human resources management information system is not only used for the traditional business management system, and more for the needs of other users, the management functions are more and more increasingly clear, changed the original closed mode, and extended to the departments of the enterprise [3].

In order to effectively meet the challenges, human resources have been recognized as one of the most important factors in today's competitive market. Great advances in information and communication technology (ICT), changing workforce mix and personal values, the emergence of the knowledge economy, and increasing global competition have created great challenges for organizations. The focus of his research is to gain insight into current HRM practices and their impact on employee satisfaction in the private banking sector in Bangladesh. For the study, 100 bank employees were selected from selected banks, and of the 88 employees who answered correctly, the answer rate was 88 percent. The questionnaire includes nine different aspects of human resource management, including recruitment and selection system, salary scheme, job security, career growth, training and development, management style, job design and responsibility, reward and incentive, and working environment. His research data is too little [4]. Guest argues that the mutually beneficial model suggests that HRM should benefit both individuals and organizations.
However, the dominant models in HRM theory and research continue to focus primarily on ways to improve performance, with employee concerns a secondary consideration. In addition, stress at work and in society more generally is posing a growing threat to the well-being of employees. If employee concerns and threats to welfare are to be taken seriously, a different framework of human resource management analysis is required. He proposes an alternative approach to human resource management that prioritizes practices aimed at improving well-being and positive employment relationships, arguing that both elements are essential. While he provides evidence in support of practice selection, he fails to demonstrate that these practices also have the potential to improve individual and organizational performance [5]. Ones et al. believes that the explosive growth of empirical research often produces contradictory results, hiding important content that can guide the evidence-based application of human resource management. The science of human resource management can turn to meta-analysis and meta-analytical thinking as an antidote to the so-called replication crisis plaguing the social sciences in general. He focuses on issues and potential problems that may threaten the accuracy and effectiveness of contemporary human resource management meta-analyses. $\mathrm{He}$ believes that the meta-analysis must address these issues correctly in order to achieve its full potential in advancing the science and practice of human resource management. $\mathrm{He}$ addresses the problem of identifying and including all relevant effect sizes, as well as appropriate fixes for unreliability and scope limitations. Although he provides specific recommendations, the inclusion of unpublished practitioner studies and data in HRM meta-analyses is unknown [6]. Chowhan et al. made a theoretical contribution by exploring the relationship between HRM practices and innovation results at the workplace level through the continuous feature approach. Innovators are classified by their degree of success in implementing new product/process and/or improved product/process results year by year. The human resource management practices explored include the use of highquality personnel, as well as subpackages of skill enhancement, incentive enhancement, and opportunity enhancement practices. In addition, he explores work organization practices, including integration and collaboration, the introduction of organizational change, and the use of technology. The findings suggest that workplaces that set strategic goals related to innovation motivate employees, create opportunities for employees to take action, and make greater use of technology tend to be more persistent innovators. Although these findings contribute to the formulation of government policies, the results of seeking to improve innovation performance are not satisfactory [7]. Crowley and Bourke believe that the ability of enterprises to maximize their innovation potential is the foundation of economic growth. The successful implementation of human resource management (HRM) practices is important to corporate performance, and there is a growing understanding of the benefits to companies when applying HRM practices together. He examines whether HRM practices are more effective when implemented as complementarities than when implemented separately in 
Irish manufacturing and service companies. The National Workplace Survey, a data set containing information on human resource management practices at the firm level, was used. Human resource management bundles related to performance management and evaluation, knowledge sharing and participation, and decision empowerment are positively correlated with innovation in manufacturing and service firms, and flexible employment contract practice bundles have a positive impact on innovation in service firms. Although human resource management is very important to enterprise innovation, it is only a theory without practice [8]. Chen et al. argue that human resources are increasingly important to East Asia's growing economies, which are trying to continue their growth by moving economically into higher value-added product markets. Human resource management (HRM) in Taiwan, based on Confucianism and influenced by western management research and practice, has undergone various significant paradigm shifts in recent years. With Taiwan's rapid economic growth and industrial and institutional transformation, human resource management in the region has been developing. Therefore, he reviewed the development of human resource management in Taiwan in recent decades. The research reviewed was collected from work published in Chinese journals of the Social Sciences Citation Index or Taiwan Social Sciences Citation Index from 1990 to 2016. He discussed in detail the development of human resource management in Taiwan and provided a summary plan and made some comparisons with human resource management in other selected economies in East Asia, including mainland China and Hong Kong economies with the same cultural lineage and values but lacking in research innovation [9]. Sandra et al. argue that although high performance HR practices do not directly affect the firm's social performance (CSP) strengths, they do have a positive impact on the CSP strengths of companies that are highly innovative or have high levels of slack. High-performance human resource management (HRM) practices can also directly and negatively impact CSP issues. Although he developed and tested his assumptions about how high-performance HRM affects the strengths and concerns of a company's CSP, this is secondary data from a third-party database [10]. With the extensive attention of talent strategy in all walks of life, the human resource management information system has been widely popularized in many foreign companies, and the application rate is very high. The products of HR management information systems are not single, from single-alone to online versions to WEB-based versions. At present, a large number of relatively well-known human resource management information system products have appeared in the foreign application market.

Basic HR information, job adjustment, transfer, or other training information will also cause high workload and low work efficiency; the promotion history and application status of human resource information management system in western developed countries have not only become the reference standard for its development prospect but also the reference and guide for enterprises to promote the use of $\mathrm{HR}$ information management system. In this research, the system development process of this research mainly uses the class library in the software architecture layer to support the software development process. The main development language of Android, JAVA, is to install the Android Develop Tools plug-in on eclipse and install the Android SDK in the computer operating system to build the Android development environment. The system has the functions of personnel management, recruitment management, attendance management, training management, work management, and salary management. The recruitment management function of the system is mainly composed of recruitment plan management, recruitment information management, talent database, etc.

\section{Research Methods}

2.1. Smart Mobile Device Operating System. A mobile device operating system is an operating system that can be used on mobile devices. Its biggest feature is that the system has open interfaces, allowing third-party openers to design various software programs. There are now more users of the three operating systems, iOS, Windows Phone, and Android, and the operating systems are constantly being updated.

The reasons why the Android development platform is widely recognized mainly include the following aspects: (1) in the development process of Android applications, you only need to have a certain JAVA foundation to easily realize the development of Android applications, and it is easy to get started. Because Android applications are developed in JAVA language, its basic principles are similar to the mechanism of J2EE, which can quickly and effectively master the work of the android development environment. (2) On the Android development platform, the SQLite database is integrated internally. With this database, developers do not need to select additional databases for implementation during the process of Android program development, which is convenient for developers' development work. (3) The Android development platform integrates a variety of practical components, which provide convenience for developers to quickly develop development work and debug software systems.

Looking at today's society, it is not difficult to find that Android has already occupied a large smartphone market and is spreading globally at an unexpected rate. At present, the number of Android application software in the market has reached millions, and people can easily download all kinds of software they need in the Android application market. The main development language of Android, JAVA, is to install the Android Develop Tools plug-in on eclipse and install the Android SDK in the computer operating system to build the Android development environment. The system development process mainly uses the class library in the software architecture layer to support the software development process.

Among them, the "person" in the person-person system refers to the people working together around them or managers, and their behavior model can be set as [11]:

$$
R_{1}=\left(K \ln S_{1}+c\right) \psi_{1} \text {, }
$$




$$
\begin{aligned}
R_{i, t}= & \eta_{0}+\alpha_{1} W_{m, t-2}+\beta_{2} W_{m, t-1}+\varepsilon_{3} W_{m, t-1}+\varepsilon_{4} W_{m, t+2} \\
& +\varepsilon_{5} W_{m, t+1}+\varepsilon_{i, t} .
\end{aligned}
$$

"Machine" in the human-machine system refers to the operating machinery and equipment, such as displays, controllers, and signal devices, and its behavior mode is $R_{2}$, then [12]:

$$
\begin{gathered}
R_{2}=\left(K \ln S_{2}+c\right) \psi_{2}, \\
Q_{i, t}=\alpha \ln \left(\phi+\varepsilon_{i, t}\right) .
\end{gathered}
$$

The "ring" in the human-circle system refers to the working environment or other stimulating factors, such as high temperature and low illumination, and its behavior mode is denoted as $R_{3}$, then [13]:

$$
\begin{gathered}
R_{3}=\left(K \ln S_{3}+c\right) \psi_{3}, \\
R_{i, t}=-\varphi\left[N(N-1)^{3 / 2} \sum W_{X}^{3}\right] .
\end{gathered}
$$

Then, the generalized model of human safety behavior can be further extended to [14]:

$$
\begin{gathered}
R=\lambda\left(R_{1}, R_{2}, R_{3}\right)=\left(\psi_{1}, \psi_{2}, \psi_{3}\right)\left(K \ln \left(S_{1}+S_{2}+S_{3}\right)+c\right), \\
L_{i, t}=\log \frac{\left[\left(c_{u}-1\right) \sum_{\text {Down }} b_{i, t}^{2}\right]}{\left[\left(d_{d}-1\right)\left(\sum_{\mathrm{UP}} \mathrm{q}_{i, t}^{2}\right)^{3}\right]} .
\end{gathered}
$$

The theory of employee rational behavior can be expressed by the following equation [15].

$$
\begin{gathered}
B \sim I=(\mathrm{AB}) \omega_{1}+(\mathrm{SN}) \omega_{2} \\
G(x \mid \text { Data })=\frac{P(x \mid \text { Data }) Q(x)}{\int P(x \mid \text { Data }) Q(x) d x} \propto K(x \mid \text { Data }) M(x) \\
F(x)=Y^{a-1}(1+Y)^{b-1}+R^{a-1}(1-Y)^{b-1} .
\end{gathered}
$$

In the above formula, $B$ is the individual's behavior under the control of the individual's will, and $I$ is the individual's behavioral intention. Staff attitude can be expressed by the following formula [16]:

$$
\mathrm{AB}=\mu \sum \mathrm{BB}_{i} \mathrm{OE} .
$$

Among them, BB (behavior beliefs) represents a significant belief in the implementation of a specific behavior. When performing a certain behavior, the employee subjective norm (subjective norm, $\mathrm{SN}$ ) is expressed as [17]:

$$
\mathrm{SN}=\sum \mathrm{NB}_{n} \mathrm{MC}_{j} .
$$

Human resource management is an important part of the internal affairs management of an enterprise. It holds the personnel information of the enterprise and plays a vital role in the survival and development of the enterprise. Enterprise human resource information can provide detailed information and data support for enterprise management and development. However, for a long time, many enterprises are still using the old human resource information management model, makes human resource management work inefficient, difficult to upgrade and maintain, and low security. According to the demand analysis, the system needs to support the PC platform web access and Android mobile client access, and the two platforms work together. Therefore, the physical environment required by the system should be composed of application servers, database servers, switches, the Internet, PC terminals, mobile communication networks, mobile terminals, routers, wireless gateways, and other equipment. The physical architecture of the system is shown in Figure 1.

\subsection{Detailed Design of Functional Modules of Human Resource Management System}

2.2.1. Design of User Management Function. The user management function is a key function that maintains the effective operation of the entire system and can work normally. Although it is an indirect business process that is more important to the system's personnel, if the system can operate normally and effectively within a predetermined range, the user management function design is still necessary. The user management function module has corresponding settings for the use authority of the system, and the system user can only enter the system interface to use the relevant functions after logging in to the system to obtain the use authority of the system. User management is a relatively basic management node in this system. At the same time, the system is mainly operated by enterprise staff, and the file management module is usually used: to protect the relevant work information of enterprise staff, but relevant data derived from the information of enterprise staff are the key part of the processing of this module, and this information mainly includes data information such as user login and authority ownership.

2.2.2. Design of Personnel Management Functions. The design of personnel management functions employee files, personnel changes, etc. are the most critical part of the personnel management work process, which is related to the stability of enterprise operation and the security of data information. This module mainly includes contract management, file management, and personnel changes wait. Among them, contract management and file management have the most basic operations of the personnel management system, such as contract management and file management, which should have a series of basic functions such as adding and deleting. After corresponding changes, corresponding changes can be made on the basis of changes.

2.2.3. Design of Recruitment Management Function. Recruitment is an important part of talent attraction in the process of human resource management. This system mainly relies on the Internet and talent recommendation in the selection 


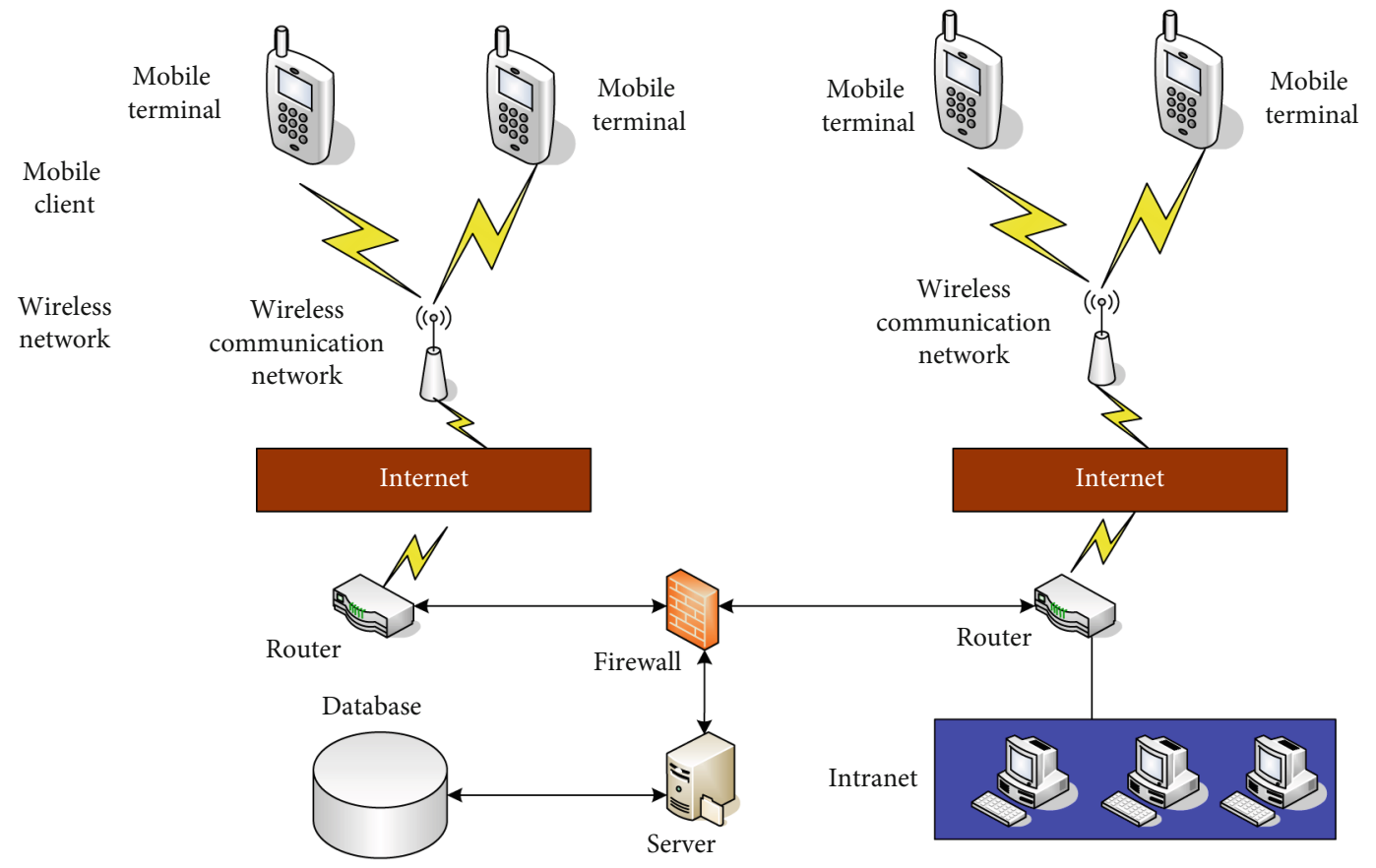

Figure 1: System physical architecture.

of talents. The recruitment management function of the system is mainly composed of recruitment plan management, recruitment information management, and talent pool. In the system's recruitment plan management function, important information such as the recruitment part, the number of recruits, personnel requirements, and the specific arrival time of the personnel must be clarified. The personnel in charge of the enterprise personnel department shall conduct corresponding regulations according to the specific needs of the enterprise, and shall be experienced by the personnel department review is carried out, and all parts of the enterprise are coordinated and completed at the same time.

The recruitment information management module is used by the personnel commissioner to operate and publish through the front end of the system. The personnel recruitment information can be forwarded by link, which is convenient for corporate staff to discover the talents around them and expand the corporate talent pool. The talent pool is mainly used to store the talent information discovered by the enterprise in the recruitment process.

2.2.4. Design of Attendance Management Function. Attendance management function module is the basis to ensure the orderly operation of the enterprise. This function module mainly includes attendance system management, dynamic management, leave management, and attendance record. Among them, the time and attendance system management is used to explain the standards of the company for the time and attendance management, including system preparation, system review, and system release.

The first condition for operating dynamic management is to perform recognition and registration, that is, to recognize the user's face information through face recognition technology and match the image of the person entered into the system in advance by the human resources department. After the recognition and registration are completed, the user can perform the corresponding operation, such as the administrator manages the commuting hours and mobile office locations of corporate staff. In the check-in function module, it should be noted that only when the check-in is in the effective area, the user's check-in operation can take effect, and the dynamic trajectory is convenient to manage the field staff and is convenient for the analysis of the working time and location images and data of the field staff. The GPS function of the mobile phone is used. Therefore, employees must open the mobile phone geographic location during work, otherwise, the system will not be able to record the dynamic trajectory of the employee, and the employee will not be able to generate the dynamic trajectory of the work. It is difficult to prove whether it is working properly. When the employee completes the check-in at work and opens the geographic location, the system will use the GPS function of the mobile phone to record the geographic location information of the employee, and associate the generation time to form a dynamic trajectory, and then the employee's working time and location images and data can be viewed. The design of the leave management module effectively reduces the enterprise human resource management process and approval time, which is convenient for operation and management. In the attendance record module, the scope of attendance records viewed by the user is also different according to different permissions.

2.2.5. Design of Training Management Function. Training management function modules mainly include training plans, training resources, training assessments, and training 
TABLE 1: Salary calculation method.

\begin{tabular}{|c|c|c|c|c|}
\hline Name & Initial value & Formula & State & Manage \\
\hline Transportation subsidy & 50.00 & No formula set & Enable & Manage \\
\hline Communication subsidy & 20.00 & No formula set & Not enabled & Manage \\
\hline Medical insurance & 1.00 & -120 & Not enabled & Manage \\
\hline Pension & 1.00 & -80 & Enable & Manage \\
\hline Be late & 1.00 & -[Number of late arrivals] $* 5$ & Enable & Manage \\
\hline Leave early & 1.00 & -[Early leave times] $* 6$ & Enable & Manage \\
\hline Absenteeism & 1.00 & -[Number of days absent from work] $* 30$ & Enable & Manage \\
\hline Travel allowance & 1.00 & [Business trip days] $* 10$ & Enable & Manage \\
\hline Personal leave & 1.00 & [Number of days on leave] $* 10$ & Enable & Manage \\
\hline
\end{tabular}

evaluations. Among them, training resources are the basis of the entire functional module. Users can publish and query training plans and related functions in the training plan module and then perform resource inspection, upload, download, and other operations in the training resource module, which realizes the recycling of resources and is effective solved the time and venue issues in the training process. In addition, the human resources department can also issue training assessment notices to organize personnel to assess the effectiveness of training, including online and offline methods. After the training and assessment are over, the training process, methods, and effects can be evaluated by the training participants, so that the training organization personnel can make corresponding improvements and enhance the company's training capabilities and effects.

2.2.6. Design of Work Management Functions. The work management function module is mainly used to arrange and manage the work of enterprise staff. The function module includes work task management, online communication, and information notification. Work task management is the main module of this function, while online communication and information notification are auxiliary effect.

Managers release the work tasks layer by layer. After receiving the tasks, the staff members will inquire and understand the task information in detail and submit the work task information, which will be fed back to the system and related personnel. The system classifies the information and automatically updates the task progress. Other coordinating personnel refer to it; and according to the completion of the work task, reward and punish those who are excellent or poor in their work. In the working process, users can also choose discussion groups to realize online video, voice, and information exchange. The face recognition technology and voice recognition technology adopted by the system can realize the real-time transmission of video information and voice information.

2.2.7. Design of Salary Management Function. By calculating how much wealth the employees of the company have contributed to the company and other factors in their own work develop a differentiated management platform to promote the work enthusiasm of the employees, and salary management is one of the important ways to stimulate the enthusi- asm of the employees and improve the enthusiasm of the employees. Therefore, when designing an enterprise human resource management system, salary management must be regarded as a key component of the system. At the same time, there is also a close connection between the salary management function module and other management modules of the system. Therefore, the design and implementation of salary management are also critical to the operation of the entire human resource management system.

Since salary management involves the actual benefits of employees, it has a very important impact on factors such as employees' work enthusiasm. It needs to calculate the work performance of each employee of the company through a certain calculation method and give clear entries and reports. And also need to be able to meet the staff's query needs for historical wages. In this system, the salary management function module mainly includes salary grade evaluation management, welfare management, and salary management. The salary calculation method is shown in Table 1.

The prediction formula of TPB (perceived behavioral control, PBC) theory on behavior is extended to the following formula $[18,19]$ :

$$
B \sim \mathrm{BI}=(\mathrm{AB}) \omega_{1}+(\mathrm{SN}) \omega_{2}+(\mathrm{PBC}) \omega_{3}
$$

Among them:

$$
\mathrm{PBC}=\sum \mathrm{PB}_{n} \mathrm{MC}_{j}
$$

Score of resource allocation factors affecting the company's profitability [20]:

$$
\begin{aligned}
\operatorname{PROF}_{j}= & w_{1 j} z \text { prof } x 1+w_{2 j} z \text { prof } x 2+w_{3 j} z \text { prof } x 3 \\
& +w_{4 j} z \operatorname{prof} x 4+w_{5 j} z \operatorname{prof} x 5
\end{aligned}
$$

Use the extracted variance contribution rate of each factor to calculate the weighted average to obtain the resource allocation (PROF) factor reflecting profitability [21]:

$$
\mathrm{PROF}=\frac{(\mathrm{PROF} 1+\mathrm{PROF} 2+\mathrm{PROF} 3)}{3} .
$$




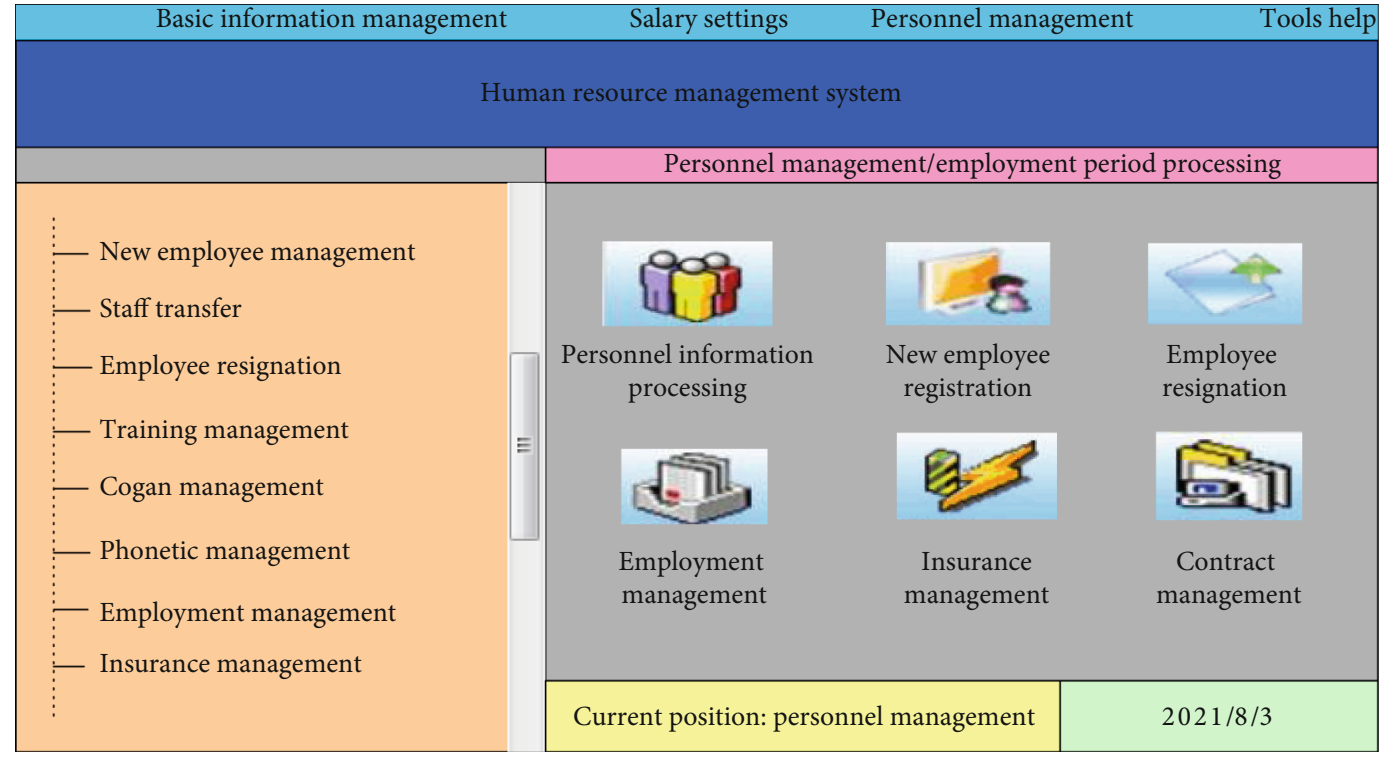

FIGURE 2: System management interface.

Calculate the scores of each factor of the company's shareholder profitable resource allocation [22]:

$$
\begin{aligned}
\mathrm{SH}_{j}= & w_{1 j} z \operatorname{sh} x 1+w_{2 j} z \operatorname{sh} x 2+w_{3 j} z \operatorname{sh} \times 3+w_{4 j} z \operatorname{sh} x 4 \\
& +w_{5 j} z \operatorname{sh} x 5 .
\end{aligned}
$$

Among them, $j=1,2,3,4,5$. Calculate the shareholder profitability resource allocation $(\mathrm{SH})$ indicator based on the variance contribution rate of each of the five main factors [23]:

$$
\mathrm{SH}=\frac{\left(\mathrm{SH}_{1}+\mathrm{SH}_{2}+\mathrm{SH}_{3}+\mathrm{SH}_{4}+\mathrm{SH}_{5}\right)}{5} .
$$

Study the impact of resource allocation, human resources, and environmental regulation effects on corporate performance Perf $[24,25]$.

$$
\text { Perf }=\alpha+\alpha_{1}+\beta_{1}+\beta_{2} \cos t+\beta_{3} \cos t+\chi .
$$

2.3. Database Selection. With the continuous and rapid development of the overall construction of China's national economy and the continuous improvement of the market economy system, coupled with the rapid development of information technology, all enterprises are through innovation, the introduction of modern scientific and technological achievements, for enterprises, for employees, for customers to improve the service level, and improve the work efficiency of employees. When the market economy is constantly optimized, opportunities and challenges coexist, and the introduction of modern equipment and facilities has also brought severe tests to enterprises to a certain extent, which has stricter standards and higher requirements for management level, administrative functions, and standardized and optimized services.
At present, there are mainly three kinds of databases, Oracle, SQL Server, and My SQL, which have strong applicability and excellent performance in the construction of the system. Among them, Oracle is a large database, SQL Server is a medium-sized database, and My SQL is a small database. My SQL is designed to be fast, efficient, and practical. It is a Web database system widely used on Linux-like servers and supports most operating system platforms. In terms of programming, My SQL also provides $\mathrm{C}++, \mathrm{C}$, Java, and other API interfaces, and even My ODBC interface, which can be used by all languages that can use ODBC interface. More importantly, the source code of My SQL is completely open and can be used for free. After comparing the databases of the human resource management system, we finally chose the My SQL database, and the mobile terminal chose the SQ Lite database built into Android [26]. The system management interface is shown in Figure 2.

\section{Results}

At present, the human resource management information system used by some companies only has the most basic applications such as data input, modification, and deletion and does not have information processing functions such as information query, information optimization, information statistics, and information analysis. From the perspective of processing work, it is a pity. Therefore, it is very meaningful to design a human resource management information system with more complete functions, standard design, and convenient operation.

This system is $\mathrm{B} / \mathrm{S}$ architecture software, and its main performance evaluation criteria are the number of concurrent users supported by the server and the average response time of users. Table 2 shows the data analysis of the functional test structure of each functional module.

Now there are a lot of enterprise managers that have realized how to use the idea of information, standardization, 
TABLE 2: Functional test structure data of each functional module.

\begin{tabular}{lccccc}
\hline Module & Number of use cases & Success & Fail & Success rate (\%) & Failure rate (\%) \\
\hline Department management & 40 & 40 & 0 & 100 & 0 \\
Attendance management & 160 & 160 & 0 & 100 & 0 \\
Personnel management & 200 & 200 & 0 & 100 & 0 \\
Performance management & 80 & 80 & 0 & 100 & 0 \\
Training & 100 & 99 & 1 & 99 & 1 \\
\hline
\end{tabular}

TABle 3: Typical business.

\begin{tabular}{lcc}
\hline Typical transaction name & Function type & Proportion of mixed trading time \\
\hline Log in & Public employee function & $20 \%$ \\
Attendance information submission & Administrator function & $20 \%$ \\
Personnel information submission & Staff function & $20 \%$ \\
Company announcement information submission & Administrator function & $20 \%$ \\
Salary information submission & Administrator function & $10 \%$ \\
\hline
\end{tabular}

TABle 4: System memory test.

\begin{tabular}{|c|c|c|c|c|}
\hline Scene name & $\begin{array}{c}\text { Successful } \\
\text { transactions }\end{array}$ & $\begin{array}{c}\text { Transaction success } \\
\text { rate }\end{array}$ & $\begin{array}{c}\text { ART_HTTP }_{(\mathrm{s})} \\
\text { A }\end{array}$ & $\begin{array}{c}\text { System host CPU } \\
\text { usage }\end{array}$ \\
\hline $\log$ in & 419 & $100 \%$ & $0.23 \mathrm{~s}$ & $25.80 \%$ \\
\hline Attendance information submission & 618 & $100 \%$ & $0.81 \mathrm{~s}$ & $31.25 \%$ \\
\hline Personnel information submission & 1873 & $98 \%$ & $0.90 \mathrm{~s}$ & $35.25 \%$ \\
\hline $\begin{array}{l}\text { Company announcement information } \\
\text { submission }\end{array}$ & 956 & $100 \%$ & $0.18 \mathrm{~s}$ & $30.37 \%$ \\
\hline Salary information submission & 857 & $100 \%$ & $0.09 \mathrm{~s}-0.5 \mathrm{~s}$ & $30.21 \%$ \\
\hline Performance information submission & 557 & $100 \%$ & $0.09 \mathrm{~s}-0.5 \mathrm{~s}$ & $32.51 \%$ \\
\hline
\end{tabular}

systematic, and modular way to manage the importance of enterprise human resources information, strive to strengthen and improve the enterprise human resources management information system construction, and began to develop or buy suitable for the company's development goals or characteristics of the human resources information management system. However, there are still many enterprise managers who have not had a clear understanding of the human resource information management system, and managers often think that starting only from the perspective of operation.

Due to the many functions of this system, such as system login, personnel, attendance, performance, salary, and announcements, and other module information submission, etc., are mixed according to different weights, in order to produce a test effect closer to the real situation. Therefore, it is necessary to test the system performance under different conditions. The typical services finally selected are shown in Table 3.

The system memory test is shown in Table 4 . From the test results and data, under various scenarios, the transaction success rate is basically $100 \%$, and the expected goal can be reached. The transaction response time in the scene is less than $1.5 \mathrm{~s}$, which is within a reasonable response time range.
TABLE 5: Summary of test results.

\begin{tabular}{lccc}
\hline $\begin{array}{l}\text { Number of } \\
\text { concurrent } \\
\text { users }\end{array}$ & $\begin{array}{c}\text { Number of } \\
\text { failed requests }\end{array}$ & $\begin{array}{c}\text { Throughput } \\
\text { (requests per } \\
\text { second) }\end{array}$ & $\begin{array}{c}\text { Request } \\
\text { time (ms) }\end{array}$ \\
\hline 5000 & 0 & 4201.47 & 119.006 \\
10000 & 0 & 3890.82 & 257.015 \\
50000 & 3 & 793.27 & 6763.387 \\
100000 & 6 & 670.92 & 14904.853 \\
\hline
\end{tabular}

Content access was tested according to the four-level concurrent user simulation test of 5000, 10000, 50000, and 100000, and the test results are summarized in Table 5.

Put the enterprise employee information manually into the computer one by one, then use the relatively simple operation of the office text or form processing software to edit it, and print out a list of employee information. Otherwise, a complete quality human resource management information system should not only have integrated centralized information source but should also have easy access and easy query database, and the purpose of the system design is to rely on modern computer processing technology to realize such a human resources information management system, 


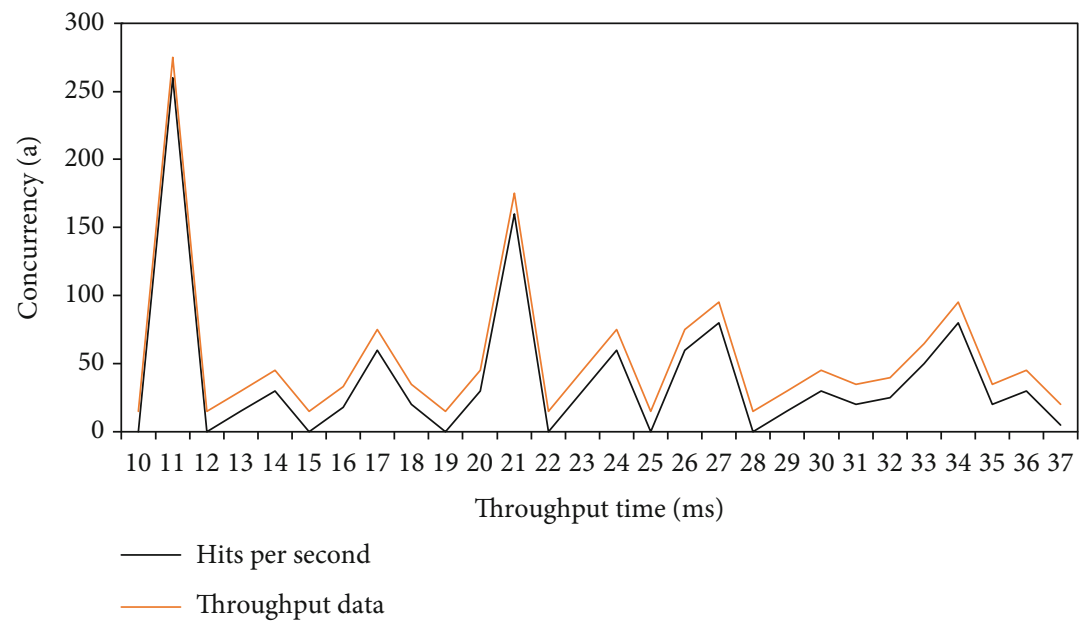

Figure 3: System hit rate and throughput per second.

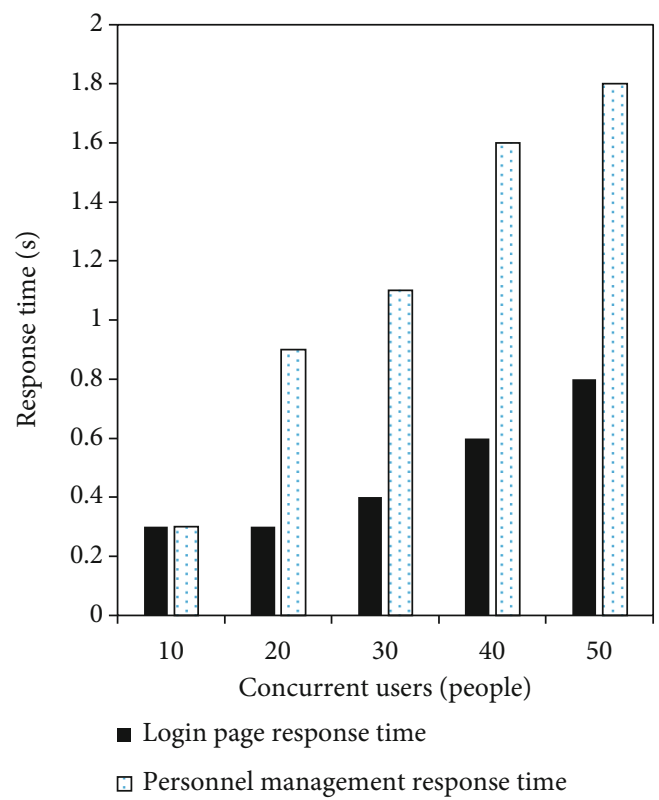

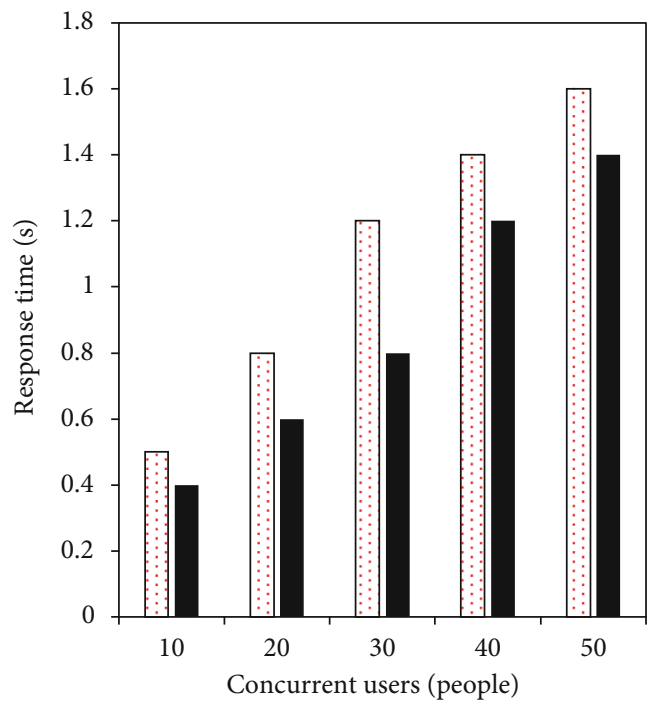

$\square$ Recruitment management response time

- Attendance management response time

Figure 4: Corresponding tests of each module.

embodies the principle of fairness in employee management, retain talent, and improve the management level of enterprise management.

It can be seen from Table 5 that as the number of concurrent users increases, the number of failed requests increases, the throughput decreases, and the request time increases. From the test results, when the number of concurrent users reaches 50,000 , the request time is about $6 \mathrm{sec}-$ onds, which meets the requirement that the response time is less than 10 seconds in the case of 10,000 people per second. During the test, the hit rate and throughput per second of the system are shown in Figure 3.

In the actual operation of the system, the maximum number of concurrent users is set to 500, and the response time of the system server is $2 \mathrm{~s}$. On this basis, this paper draws up a specific test plan, that is, 100 users are drawn to log in and access the system functions, and then 100 peo- ple are added every 10 seconds to test the response time of the system. Until the number of concurrent users of the system reaches 500, it stops, and see if the response time of the system exceeds $2 \mathrm{~s}$. Subsequently, a number of repeated tests were carried out according to this test plan, the problems existing in the test process were summarized, and the overall evaluation of the system performance was finally made. The corresponding test of each module is shown as in Figure 4.

After completing the system performance test, a number of performance tests need to be performed on the performance of the Android client in this article to ensure that the system's functions are successfully displayed on the Android client. The interface of the Android mobile phone client is shown in Figure 5.

This article selects the mainstream Android mobile phone brands in multiple markets for system performance testing and mobile phone memory monitoring at the same 


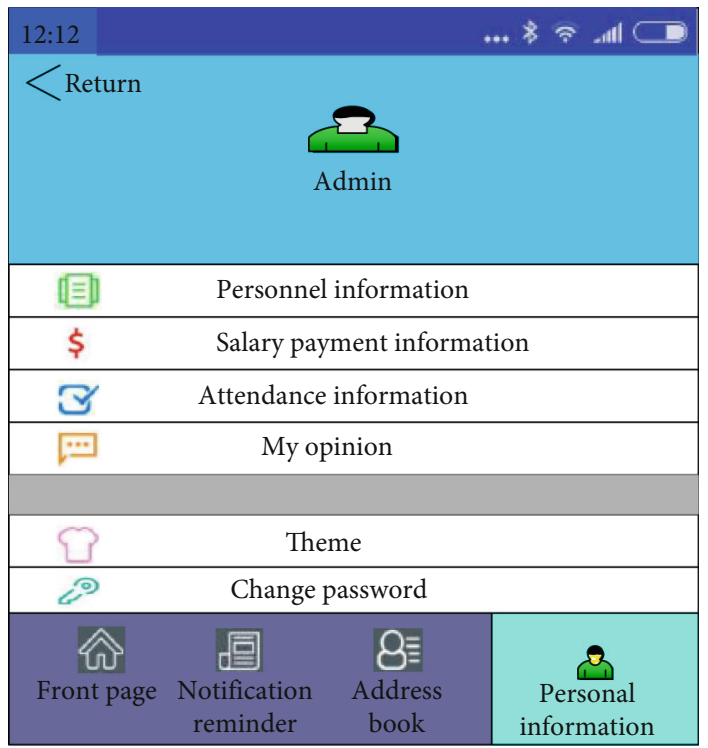

FIgURE 5: Android mobile phone client interface display.

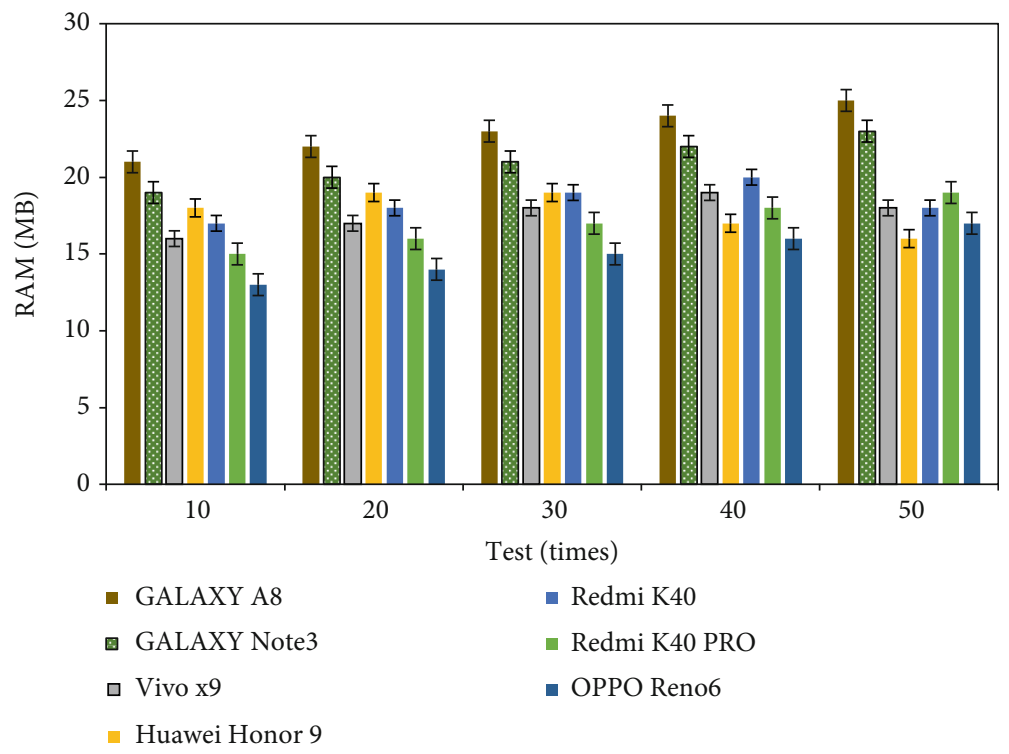

FIgURE 6: Memory monitoring test results of multiple mobile phone brands.

time. The results show that, except for Samsung mobile phones that will cause the system to stutter occasionally in terms of system memory usage, the rest of the Android mobile phone clients can guarantee the overall operation of the enterprise human resource management system. The memory monitoring test results of multiple mobile phone brands are shown in Figure 6.

Since the system is researched and developed on the basis of Web technology, it is necessary to test whether the system can withstand various pressures from the operation of network users. This system uses a pressure test to verify system performance indicators. The system introduces the load runner test tool to check the system pressure. The system pressure is shown in Figure 7.
The system performance test adopts the method of increasing pressure for testing. It is expected that the total number of enterprise human resources and related operators will be about 300 at most. The test is conducted according to the pressure target of the limit value of 400 people. Under the maximum pressure, the system query response speed is faster, in line with the expected nonfunctional target requirements. Through system testing, it can also be concluded that the system has functional and nonfunctional expected target requirements and has the technical conditions for putting it into operation.

Some employees of company Y were randomly selected as the subjects of this survey. Y company has 216 full-time employees, and the proportion of employees with different educational backgrounds is shown in Figure 8. 

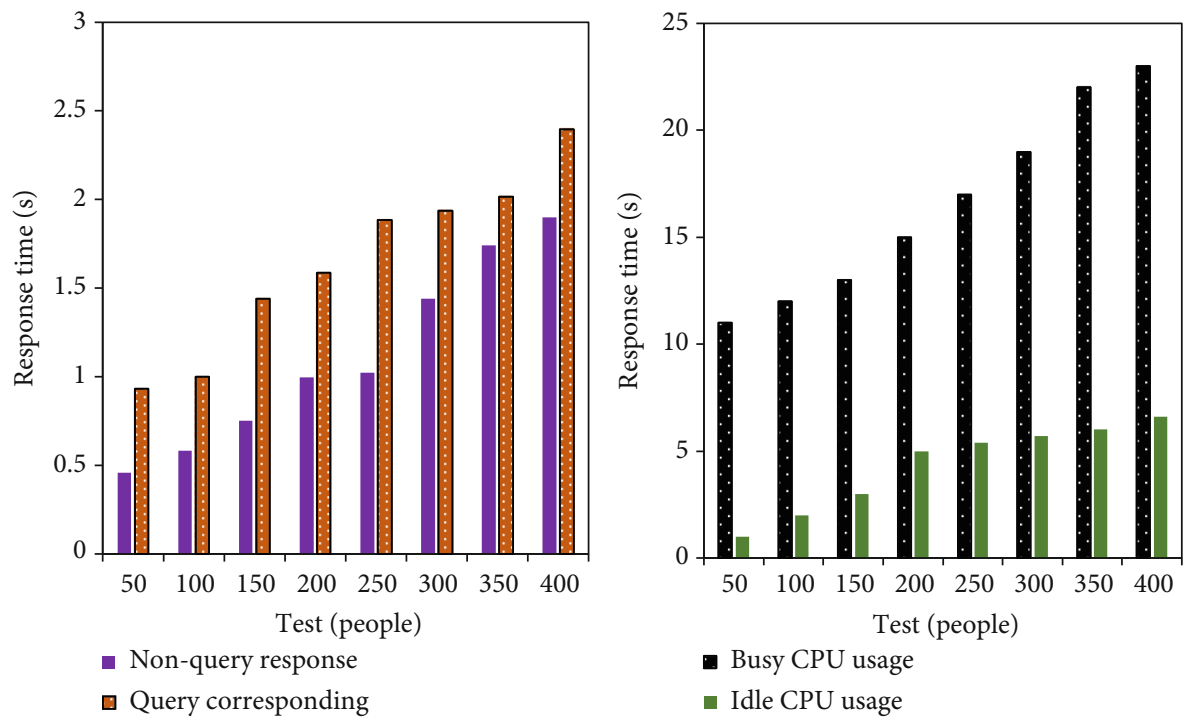

Figure 7: System pressure.
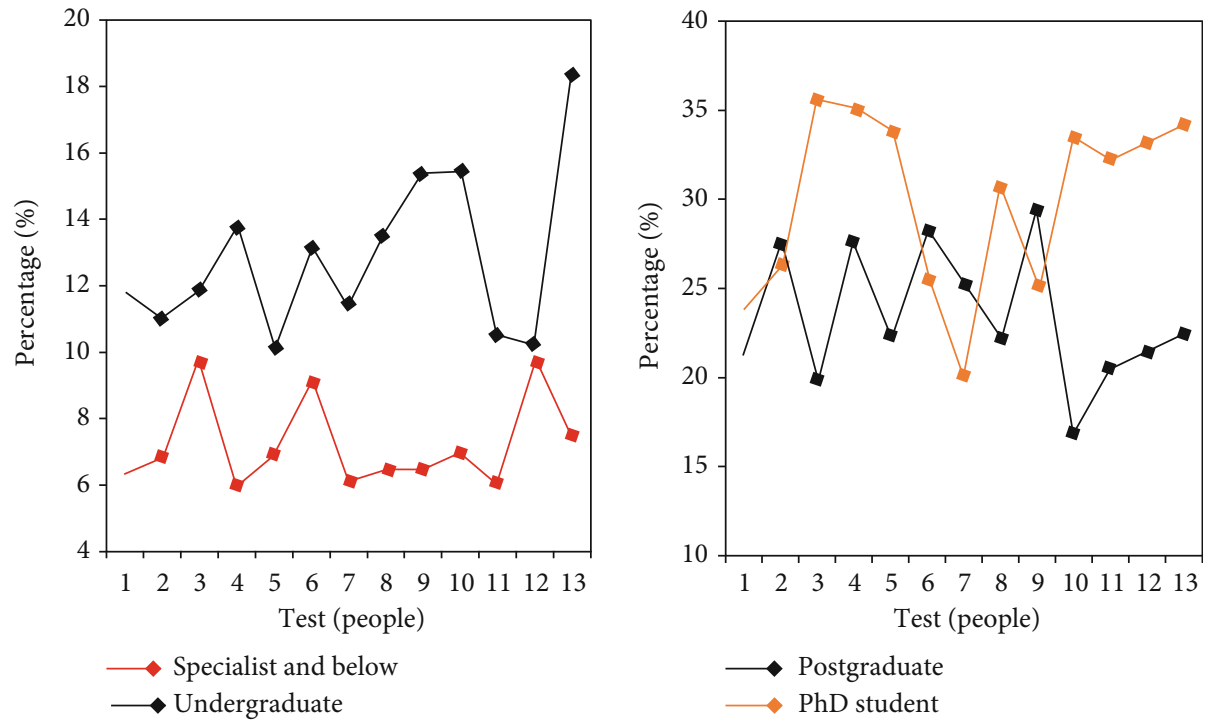

FIGURE 8: Proportion of employees with different educational backgrounds.

The company's human resources team has the highest recognition of the "culture and identity" dimension and has a highly consistent culture and values; the cognitive consistency of the "strategic vision" is relatively low. The results of the organizational effectiveness survey are shown in Figure 9.

Analyzing the survey data, it can be concluded that the human resource management model of company Y conforms to the self-development goals of employees, has a complete performance appraisal system, a reasonable salary system, and conforms to the company's long-term development plan and goals, and is practical. The employee satisfaction degree of Y company's human resource management model is shown in Figure 10.

\section{Discussion}

Enterprises need to adopt a series of management methods to promote employees' positive emotional cognition and evaluation of labor relationship satisfaction, in order to further realize the cross-level transformation of strategic human resource management to work performance. For example, companies not only need to provide employees with more satisfactory labor remuneration, growth and development opportunities, and labor conditions and security, but at the same time, companies should also pay attention to the individual labor load of employees, such as fair labor distribution, employee pressure perception, and labor time $[27,28]$. 


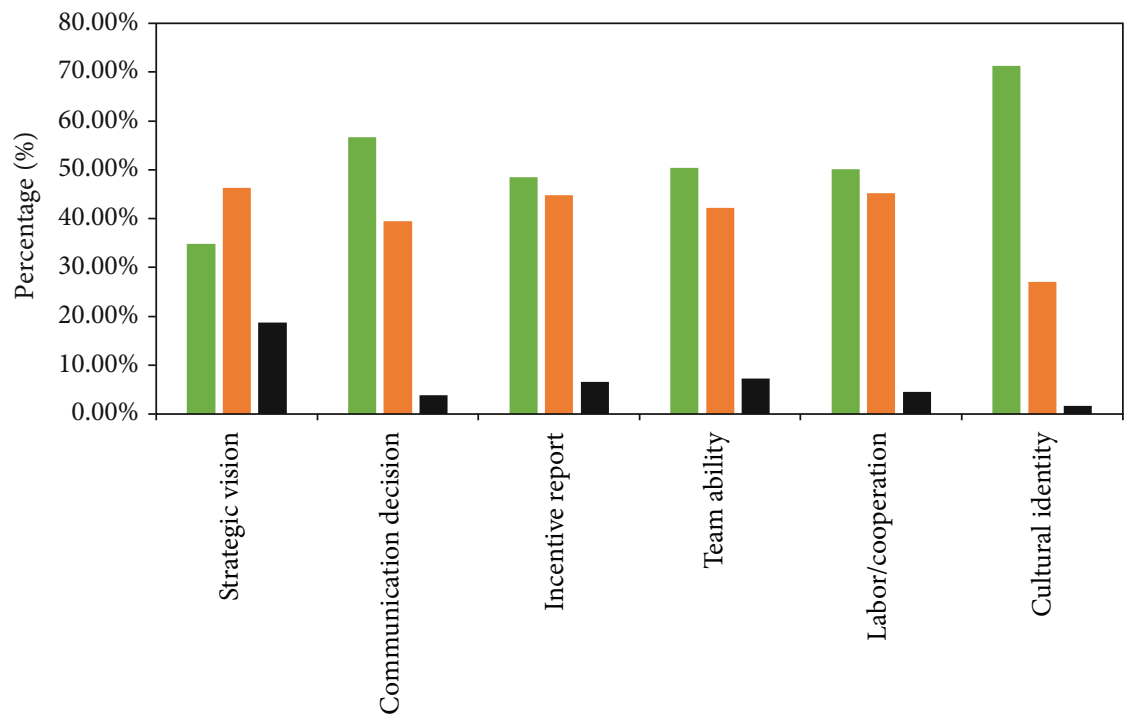

\footnotetext{
- Agree

- Generally

- Disagree
}

Organizationl effectiveness dimension

Figure 9: Results of organizational effectiveness survey.
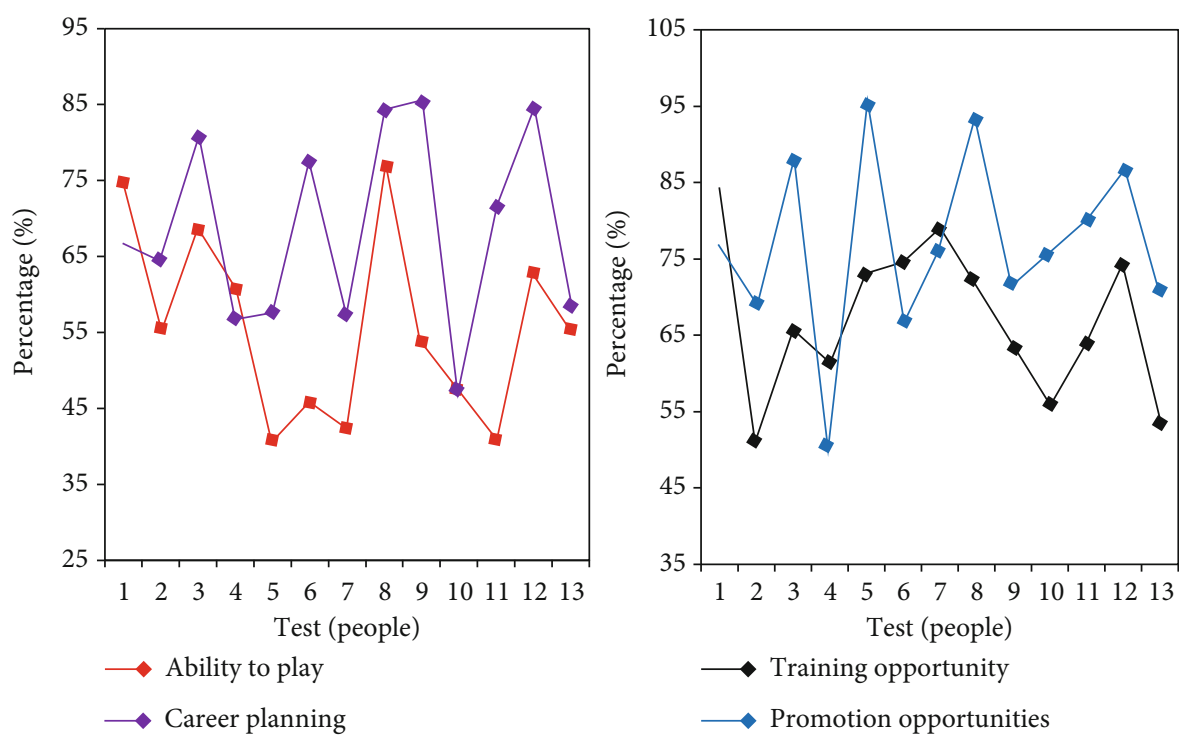

FIgURE 10: Employee satisfaction of Y company's human resource management model.

Self-selection through company reputation or job characteristics: employees know more about their suitability for their jobs than the organization. When an employee is applied to a specific organization, he must first understand the reputation of the organization, such as the company's social reputation-environmental protection, community participation, relationship with the government, human resources reputation, and whether it is consistent with their own corporate social responsibility values. In the case of a match, the employee balances himself and then makes a decision. When human resource management conducts staffing and selection, the first consideration is whether employees agree with the values of the company, especially whether the company agrees with the values of creating and enhancing benefits for stakeholders, and second, whether employees, as stakeholders of the company, have fulfillment willingness and ability of the stakeholders to include their own social responsibilities, so in the staffing and selection, corporate social responsibility is an important factor affecting the selection and allocation [29].

The human resource management information system has changed the focus of the human resource management department, can help human resource managers free from trivial administrative affairs, changed the past human 
resource workers engaged in a large number of complicated daily tasks, and rarely participated in the formulation of corporate strategies situation. The human resource management information system has promoted the process of human resource reform. The human resource management department can no longer only provide simple human resource information and can provide decision-making support to the management anytime and anywhere, which can enable the human resource management department to truly enter the "management" role of strategic partners [30]. The human resource management information system improves the objectivity and transparency of human resource management and eliminates human factors through the implementation of standard business processes, which is very beneficial to achieve the consistency of human resource management behavior. The work performance of individual employees can effectively improve the overall performance of the organization. Therefore, if an organization wants to reduce the harmful interference to its long-term development and stable performance, it needs to pay attention to which effective human resource management measures can promote the individual performance of employees. Companies can take, for example, strengthening employees' career planning to effectively improve the work results of employees under formal role requirements and further strengthen the extra-role behaviors of employees that support the technical core of the organization [31].

\section{Conclusion}

This article uses mobile network communication technology to design and implement such an information system on enterprise human resource management for the Android environment. This system is an Android-oriented human resources information management system. The ultimate goal is to provide a platform that can manage human resources information and publish announcements and notifications; all kinds of users log in to the platform we provide through the mobile client program or the web. This platform has functions such as publishing and viewing notifications, setting department information, maintaining user information, recording attendance information, and maintaining and viewing salary information. In the follow-up research, the integration research framework of human resource management and labor relations should be explored more extensively and systematically under the more advanced integration concept in the field of labor relations.

\section{Data Availability}

No data were used to support this study.

\section{Conflicts of Interest}

No potential competing interests in my paper. I confirm that the content of the manuscript has not been published or submitted for publication elsewhere.

\section{Acknowledgments}

This work was supported by Key projects of Humanities and Social Sciences in Anhui Province (SK2020A0649).

\section{References}

[1] S. B. Tsai, "Using the DEMATEL model to explore the job satisfaction of research and development professionals in China's photovoltaic cell industry," Renewable and Sustainable Energy Reviews, vol. 81, pp. 62-68, 2018.

[2] S.-B. Tsai, C.-Y. Huang, C.-K. Wang et al., "Using a mixed model to evaluate job satisfaction in high-tech industries," PLoS One, vol. 11, no. 5, article e0154071, 2016.

[3] Z. Lv, R. Lou, and A. K. Singh, "AI empowered communication systems for intelligent transportation systems," IEEE Transactions on Intelligent Transportation Systems, 2021.

[4] M. Majumder, "Human resource management practices and employees' satisfaction towards private banking sector in Bangladesh," International Review of Management \& Marketing, vol. 2, no. 1, pp. 52-58, 2017.

[5] D. E. Guest, "Human resource management and employee well-being: towards a new analytic framework," Human Resource Management Journal, vol. 27, no. 1, pp. 22-38, 2017.

[6] D. S. Ones, C. Viswesvaran, and F. L. Schmidt, "Realizing the full potential of psychometric meta-analysis for a cumulative science and practice of human resource management," Human Resource Management Review, vol. 27, no. 1, pp. 201-215, 2017.

[7] J. Chowhan, F. Pries, and S. Mann, "Persistent innovation and the role of human resource management practices, work organization, and strategy," Journal of Management \& Organization, vol. 23, no. 3, pp. 456-471, 2017.

[8] F. Crowley and J. Bourke, "The influence of human resource management systems on innovation: evidence from Irish manufacturing and service firms," International Journal of Innovation Management, vol. 21, no. 1, article 1750003, 2017.

[9] S. Y. Chen, C. H. Chuang, and S. J. Chen, "A conceptual review of human resource management research and practice in Taiwan with comparison to select economies in East Asia," Asia Pacific Journal of Management, vol. 35, no. 1, pp. 213239, 2018.

[10] S. Rothenberg, C. E. Hull, and Z. Tang, "The impact of human resource management on corporate social performance strengths and concerns," Business \& Society, vol. 56, no. 3, pp. 391-418, 2017.

[11] H. Sayyadi Tooranloo, M. H. Azadi, and A. Sayyahpoor, "Analyzing factors affecting implementation success of sustainable human resource management (SHRM) using a hybrid approach of FAHP and type-2 fuzzy DEMATEL," Journal of Cleaner Production, vol. 162, pp. 1252-1265, 2017.

[12] N. N. Brueller, A. Carmeli, and G. D. Markman, "Linking merger and acquisition strategies to postmerger integration: a configurational perspective of human resource management," Journal of Management, vol. 44, no. 5, pp. 1793-1818, 2018.

[13] A. Korauš, Z. Kaščáková, V. Parová, and S. Veselovská, "Sustainable economic development through human resource management: social inteligence of managers and performance," Journal of Security and Sustainability Issues, vol. 6, no. 3, pp. 457-477, 2017.

[14] S. Haneda and K. Ito, "Organizational and human resource management and innovation: which management practices 
are linked to product and/or process innovation?," Research Policy, vol. 47, no. 1, pp. 194-208, 2018.

[15] D. Nguyen, S. T. T. Teo, and M. Ho, "Development of human resource management in Vietnam: a semantic analysis," Asia Pacific Journal of Management, vol. 35, no. 1, pp. 241-284, 2018.

[16] M. Diaz-Fernandez, S. Pasamar-Reyes, and R. Valle-Cabrera, "Human capital and human resource management to achieve ambidextrous learning: a structural perspective," BRQ Business Research Quarterly, vol. 20, no. 1, pp. 63-77, 2017.

[17] M. Bohlouli, N. Mittas, G. Kakarontzas, T. Theodosiou, L. Angelis, and M. Fathi, "Competence assessment as an expert system for human resource management: a mathematical approach," Expert Systems with Applications, vol. 70, pp. 83102, 2017.

[18] E. M. Olson, S. F. Slater, G. Hult, and K. M. Olson, “The application of human resource management policies within the marketing organization: the impact on business and marketing strategy implementation," Industrial Marketing Management, vol. 69, pp. 62-73, 2018.

[19] A. Corominas, A. Lusa, and R. Pastor, "Human resource management using working time accounts with expiry of hours," Journal of Industrial \& Management Optimization, vol. 5, no. 3, pp. 569-584, 2009.

[20] A. Podger, "Enduring challenges and new developments in public human resource management," Review of Public Personnel Administration, vol. 37, no. 1, pp. 108-128, 2017.

[21] D. Nie, A. M. Lamsa, and R. Pucetaite, "Effects of responsible human resource management practices on female employees' turnover intentions," Business Ethics A European Review, vol. 27, no. 1, pp. 29-41, 2018.

[22] R. E. Kidwell, K. A. Eddleston, and F. W. Kellermanns, "Learning bad habits across generations: how negative imprints affect human resource management in the family firm," Human Resource Management Review, vol. 28, no. 1, pp. 5-17, 2018.

[23] I. Kessler, P. Heron, and K. Spilsbury, "Human resource management innovation in health care: the institutionalisation of new support roles," Human Resource Management Journal, vol. 27, no. 2, pp. 228-245, 2017.

[24] T. Bartram, J. Cavanagh, and R. Hoye, "The growing importance of human resource management in the NGO, volunteer and not-for-profit sectors," The International Journal of Human Resource Management, vol. 28, no. 14, pp. 19011911, 2017.

[25] C. Gill, "Don't know, don't care: an exploration of evidence based knowledge and practice in human resource management," Human Resource Management Review, vol. 28, no. 2, pp. 103-115, 2018.

[26] S. V. Shet, T. Poddar, F. Wamba Samuel, and Y. K. Dwivedi, "Examining the determinants of successful adoption of data analytics in human resource management - a framework for implications," Journal of Business Research, vol. 131, no. 3, pp. 311-326, 2021.

[27] N. Miranda and W. Fernando, "The impact of human resource management practices of the managers on perceived organizational performance-a study on Ceylon Fisheries Corporation in Sri Lanka," Open Access Library Journal, vol. 7, no. 12, pp. 1-21, 2020.

[28] S. Amarneh and R. Muthuveloo, "Human resource management practices and person-organization fit towards nurses' job satisfaction," Management Science Letters, vol. 10, no. 14, pp. 3198-3206, 2020.

[29] J. K. Oh, C. G. Jang, and S. H. Hong, "A study on the influence of strategic human resource management in the airline industry on job satisfaction, organizational performance and customer orientation," Journal of Tourism and Leisure Research, vol. 32, no. 7, pp. 413-430, 2020.

[30] I. Putra, A. L. Hardhika, and N. Susanti, "The strategy of small and medium enterprises in the implementation of green human resource management in Bandung Regency," Budapest International Research and Critics Institute (BIRCI-Journal) Humanities and Social Sciences, vol. 3, no. 4, pp. 3341-3352, 2020.

[31] M. H. Khan and S. N. Muktar, "What's next for green human resource management: insights and trends for sustainable development," International Journal of Sustainable Development and Planning, vol. 16, no. 1, pp. 181-194, 2021. 